\title{
A mathematical model to describe the change in moisture distribution in maize starch during hydrothermal treatment
}

\author{
Ikbal Zarguili, ${ }^{1}$ Zoulikha Maache-Rezzoug, ${ }^{1} *{\text { Catherine } \text { Loisel }^{2} \& \text { Jean-Louis Doublier }}^{3}$ \\ 1 Université de la Rochelle, Laboratoire LMTAI, av. M. Crépeau, 17042 La Rochelle, France \\ 2 Laboratoire GEPEA, ENITIAA rue de la Géraudière, BP 82225, 44322 Nantes Cedex 3, France \\ 3 UPCM-INRA, BP 71627, 44316 Nantes Cedex 3, France
}

(Received 9 October 2006; Accepted in revised form 19 April 2007)

Summary Instantaneous Controlled Pressure Drop, 'Détente Instantanée Contrôlée' (DIC) was performed on standard maize starch at residual moisture content $(\sim 12 \%)$. Changes in moisture distribution were observed during the treatment and modelled through a phenomenological model based on gravimetric data. The model proposes an exponential variation in the moisture content with processing time at various pressures. The predicted data were found to be in good agreement with experimental data. The values of water activity coefficient $(\gamma)$ obtained from the model decrease, when processing pressure increases; 5.86, 3.71 and 3.36 (dry basis $)^{-1}$ for 1, 2 and 3 bar, respectively. The mass transfer coefficient decreases, when the pressure increases. Its value ranged from $5.89 \times 10^{-5} \mathrm{~m} \mathrm{~s}^{-1}$ for 1 bar down to $0.92 \times 10^{-5} \mathrm{~m} \mathrm{~s}^{-1}$ for 2 bar and $0.77 \times 10^{-5} \mathrm{~m} \mathrm{~s}^{-1}$ for 3 bar. This coefficient is not only controlled by a simple resistance to the mass transfer, but also by gelatinisation phenomenon that progresses when temperature increases.

Keywords Hydrothermal treatment, maize starch, mass transfer, moisture content, water activity.

\section{Introduction}

Starch is the most abundant reserve carbohydrate. This biopolymer is used in various industries, e.g. pharmaceutical, textile, chemical and especially in the food industry. In this field, it is used as a thickener, gelling agent, bulking agent and water retention agent (Singh et al., 2003). Pregelatinised starches are widely used for many food items as cold soluble thickeners. Several methods are used for manufacturing physically modified starch that include, drum dryer (Vallous et al., 2002), extrusion cooking (Mercier, 1987; Barron et al., 2000; Brümmer et al., 2002), annealing (Jacobs et al., 1998; Tester et al., 2000), and heat moisture treatment (Kulp \& Lorenz, 1981; Hoover \& Manuel, 1996; Collado \& Corke, 1999; Lim et al., 2001; Gunarante \& Hoover, 2002). All these methods require previous hydration of starch before physical treatment. The originality of the proposed method compared to other physical treatments is that the starches are treated at residual moisture content and no hydration step is required.

*Correspondent: Fax: + 3305464586 16;

e-mail: zrezzoug@univ-lr.fr
The 'Détente Instantanée Contrôlée' (DIC) hydrothermal treatment method was used to manufacture starches with various degrees of gelatinisation and to modify their functional properties. This process was developed in our laboratory (Rezzoug et al., 2000) some years ago. The DIC treatment consists of applying a vacuum before injection of saturated steam at a fixed pressure into a vessel containing starch at residual moisture content $(\sim 12 \%)$. This step is followed by a sudden decompression towards vacuum.

Preliminary study on standard and waxy maize starches (Loisel et al., 2006) showed a partial gelatinisation of treated samples. The occurrence of partial gelatinisation for DIC treated starches was clearly attested by an increase in the median volume diameter in cold water, decrease in the gelatinisation enthalpy and a loss of birefringence under polarised light. This was more prominent for the highest pressure and the longest time: $2.7-3$ bar for $200-300 \mathrm{~s}$.

During hydrothermal treatment of starchy foods, some physical and chemical processes take place under water and heat effects (Turhan \& Sağol, 2004). The analysis of heat and mass transfer in these systems is very important because food properties change with temperature and water migration. For example, the 
diffusion of water into the grain during steaming of cereal grains is associated with starch gelatinisation phenomenon (Stapley et al., 1999; Fang \& Chinnan, 2004). Simulation of boiling or steaming of a cereal grain using a mathematical model requires precise information regarding the water diffusivity and starch gelatinisation rate; both being dependent on moisture content and temperature. The water diffusivity in starch/water mixtures was recently measured by Gomi et al. (1998) using Pulsed-Field-Gradient NMR method (PFG-NMR). The authors reported that the water diffusivity decreased as starch gelatinisation progressed. They argued that water may be absorbed into the starch granules to form another aqueous phase into which dissolution of carbohydrate polymer may take place. This dissolution rises with the progress of gelatinisation and increases the polymer concentration in the aqueous phase resulting in decrease in water diffusivity.

NMR imaging experiments (Stapley et al., 1997) have shown that the moisture content distributions of steamed wheat grains are uniform. According to Stapley et al. (1999), gravimetric data are sufficient to enable the analysis of the time evolution of the moisture. Maruta et al. (1994) observed that the combination of reduced pressure of heat moisture treated starch allows homogeneous diffusion of steam and effective heat transfer to the starch granules. During DIC treatment, starch is heated by the latent heat of vapor condensation that causes an increase in the moisture content. This variation in moisture content can be modeled through a simple model based on gravimetric data.

In a recent study (Zarguili et al., 2006), we tested three thicknesses of maize starch (1.5, 1 and $0.5 \mathrm{~cm}$ at $3 \mathrm{bar})$ to examine the homogeneity of DIC treatment. The temperature and the moisture content were measured at the bottom and on the surface of the sample. The results showed an absence of temperature and moisture content gradients only for $0.5 \mathrm{~cm}$ thickness. For this thickness, the time to reach the equilibrium temperature was 80 , 60,45 and $20 \mathrm{~s}$ for starch treated at 2, 3, 4 and 5 bar, respectively.

The objectives of this study were to: (i) apply a mathematical model, which quantifies the mass transfer during DIC treatment of maize starch, based on experimental observations; (ii) validate the model by comparing the predictions with experimental data. The interest of the mathematical model is the determination of water content whatever be the process conditions.

\section{Materials and methods}

\section{Raw materials}

Standard maize starch at moisture content of $12 \%$ (wet basis) was supplied by Roquette Frères (Lestrem, France).

\section{Moisture content}

The starch moisture content was determined by air oven at $105^{\circ} \mathrm{C}$ during $24 \mathrm{~h}$, according to the A.F.N.O.R (Association Française de Normalisation) standard method.

\section{DIC hydrothermal treatment}

The equipment and procedure of DIC hydrothermal treatment were largely described in previous studies (Rezzoug et al., 2000; Zarguili et al., 2006). During the treatment, $22 \mathrm{~g}$ of standard maize starch $(12 \%$ wet basis) disposed in circular containers (diameter: $20 \mathrm{~cm}$; height: $5 \mathrm{~cm}$ ) were placed in the processing vessel. An initial vacuum (50 mbar) was established. As demonstrated by Zarguili (2006), this initial vacuum allows to reduce the resistance of air and then to facilitate the diffusion of steam into the product. Consequently, the time necessary to reach the steam temperature equilibrium is reduced. Saturated steam was introduced into the vessel at fixed pressure and maintained for a predetermined time. In this study, the processing pressure was fixed at 1, 2 and 3 bar. This step is followed by an abrupt decompression towards vacuum (50 mbar). After the vacuum phase, atmospheric air is injected to return to atmospheric pressure for sample recovery.

\section{Moisture content measurements during DIC treatment}

The measurements of moisture content of starch during the hydrothermal treatment were carried out for three processing pressures: 1, 2 and 3 bar. For each pressure level, the moisture content was determined at different processing times.

For a real estimation of moisture content during the DIC cycle, the sudden decompression was suppressed and replaced by a progressive depressurisation to return to atmospheric pressure to prevent the autoevaporation phenomenon that may disturb the true value of absorbed water. The eliminated quantity is mainly related to the pressure difference between processing and vacuum pressures (Maache-Rezzoug et al., 2002). Five samples were taken for the moisture content measurement. Three replicates were performed and the obtained average values were $0.2 \%$ (dry basis) at 1 bar and $0.6 \%$ (dry basis) at 2 and 3 bar.

The moisture contents were evaluated as follows:

$$
W_{\mathrm{db}}=\frac{m-m_{\mathrm{d}}}{m_{\mathrm{d}}}
$$

Where $m$ is the total mass of treated starch at $t$ time $(\mathrm{kg})$, $m_{\mathrm{d}}$ is the mass of dry starch and $W_{\mathrm{db}}$ is the moisture content at $t$ time (dry basis). 


\section{Results and discussion}

\section{Moisture content profile in starch during DIC treatment}

The moisture content follow-up of the starch during DIC treatment for various pressure levels were carried out until saturation. This state is reached when the equilibrium between the starch and surrounding is established. Plots of moisture content (dry basis) vs. DIC processing time at 1 bar $\left(100{ }^{\circ} \mathrm{C}\right), 2$ bar $\left(122^{\circ} \mathrm{C}\right)$ and 3 bar $\left(135^{\circ} \mathrm{C}\right)$ are presented in Fig. 1. It shows that the moisture content increased as processing time increased and reached an equilibrium for the pressures of 1 and 2 bar. However, the measure of moisture content beyond 60 min for 3 bar could not be carried out because of the formation of a compact lump making measurement difficult. One can see in Fig. 1 that it is the rapid absorption process, which is dominant in the initial stage (for low processing time) of the change in moisture content in starch granule. However, in the middle stage, the rise in moisture content is reduced and the gelatinisation phenomenon dominates. In the terminal stage, the moisture content reaches an equilibrium value. A greater uptake of water occurs at 3 and 2 bar. At 1 bar steam pressure, the moisture equilibrium of about $17 \%$, is reached after 30 min of DIC treatment. For the same time, the moisture content is $23 \%$ for 2 bar and the time to reach equilibrium $(26 \%)$ is longer, approximately $60 \mathrm{~min}$. For 3 bar, the same rate of moisture content uptake is observed as for 2 bar, except that the saturation level is not reached. The rise in moisture content is governed by the gelatinisation process. Takeuchi et al. (1997) showed that the moisture content in a rice grain, when kept in contact with excess

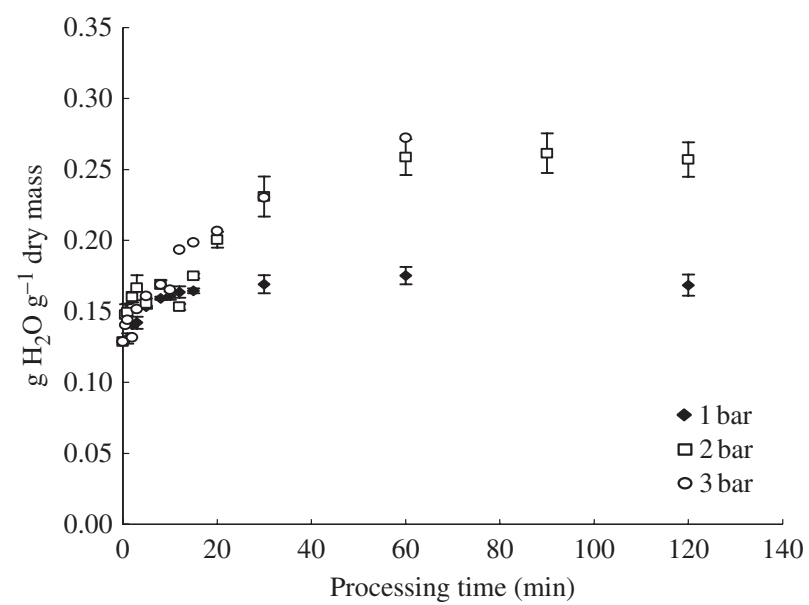

Figure 1 Moisture content of standard maize starch treated by 'Détente Instantanée Contrôlée' treatment at 1, 2 and 3 bar. water, increases with time without exceeding 43\% (dry basis) if the temperature remains below $60{ }^{\circ} \mathrm{C}$.

\section{Model equations}

The development of the model was based on two distinct stages of DIC treatment as shown in Fig. 2:

(a) Initial phase, where the starch is heated from initial temperature $\left(40{ }^{\circ} \mathrm{C}\right)$ to the saturated steam temperature (Fig. 2a),

(b) Principal phase of hydrothermal treatment, when the starch reached the equilibrium temperature (Fig. 2b).

These two phases result in two distinct time scales. The first one is around a few seconds, it was estimated in a previous study by Zarguili et al. (2006) on standard maize starch at 80,70 and $60 \mathrm{~s}$ for 1,2 and 3 bar, respectively. In contrast, the principal phase duration is about $1 \mathrm{~h}$.

In the present analysis, the simultaneous processes of heat and mass transfer are examined according to the following assumptions: the moisture content $(W)$ within the granules (thin starch layer) is spatially uniform during DIC treatment, because of the rapid heat diffusion across the granule (starch layer), the temperature $(T)$ is also considered spatially uniform and the heat of gelatinisation is neglected. The model of the evolution in the moisture content during DIC treatment is developed on the basis of experimental observations. The equations are established by considering a mass and heat balance on the starch layer. During starch

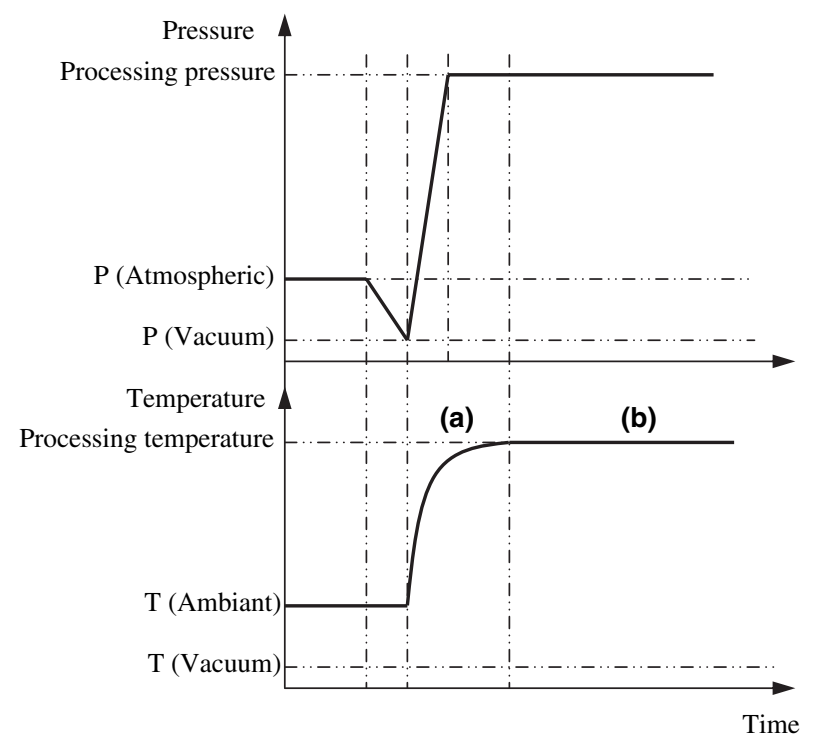

Figure 2 Schematic diagram of evolution of starch layer temperature and the surrounding vapor pressure during 'Détente Instantanée Contrôlée' treatment. 
hydrothermal treatment by DIC, the heat transfer is carried out mainly by the heat released when the steam condenses onto the matter, thus by absorption of the latent heat of condensation. The absorption of heat during gelatinisation can be considered, but this is negligible in comparison with the latent heat of phase change. Stapley et al. (1999) also considered this heat quantity negligible during the steaming of whole wheat grains. The enthalpy of gelatinisation of maize starch is approximately $12 \mathrm{~J} \mathrm{~g}^{-1}$, whereas the latent heat released to increase the moisture of the starch from $10 \%$ to $30 \%$ is approximately $440 \mathrm{~J} \mathrm{~g}^{-1}\left(=2200 \mathrm{~J} \mathrm{~g}^{-1} \times 0.2\right)$.

\section{Analysis of the initial heating phase}

In this phase, the principal heating source of the starch results from the transfer of latent heat of condensation of steam onto the starch granules. This heating raises the granules' temperature from room temperature to the steam temperature. As the variation in temperature is important, the quantity of condensed water is significant and causes a rapid increase in the starch moisture content. The short duration of this phase does not make it possible to perform measurements; we evaluated the moisture content only at the end of the initial phase corresponding also to the beginning of the second phase.

We can thus consider that latent heat associated with the moisture content absorbed by the starch granules is equal to sensible heat in the granule, when its temperature reaches that of saturated steam. The heat transfer by convection was neglected as this phase takes few seconds. The treated starches do not have enough time to absorb heat by convection. The heat balance can be than written as follows:

$$
\lambda\left(m_{\mathrm{o}}-m_{\mathrm{i}}\right)=C_{\mathrm{po}} m_{\mathrm{i}}\left(T_{\mathrm{st}}-T_{\mathrm{i}}\right)
$$

Where $m_{\mathrm{o}}$ is the total mass of the starch at the end of the initial phase $(\mathrm{kg}), m_{\mathrm{i}}$ is the initial total mass of untreated starch $(\mathrm{kg}) ; T_{\mathrm{i}}$ is the initial temperature of starch before injection of the steam $(\mathrm{K}) ; T_{\mathrm{st}}$ is steam temperature $(\mathrm{K})$; $C_{\mathrm{po}}$ is specific heat of untreated starch $\left(1.58 \mathrm{~kJ} \mathrm{~kg}^{-1} \mathrm{~K}^{-1}\right)$ and $\lambda$ is the enthalpy of condensation/absorption and can be approximated using the following formula: $\lambda=2500.8-2.48 \quad\left(T_{\mathrm{st}}-273.15\right)$ $\left(\mathrm{kJ} \mathrm{kg}^{-1}\right)$.

The mass of the starch layer after the initial heating phase is given by the following equation:

$$
m_{\mathrm{o}}=m_{\mathrm{i}}\left[1+\frac{c_{\mathrm{po}}}{\lambda}\left(T_{\mathrm{st}}-T_{\mathrm{i}}\right)\right]
$$

From this equation we can deduce the value of the moisture content (dry basis) of starch layer at the end of the initial heating phase by substituting $m_{\mathrm{o}}$ in eqn 1 .

$$
W_{\mathrm{dbo}}=W_{\mathrm{i}}+\frac{C_{\mathrm{p} 0}}{\lambda}\left(W_{\mathrm{i}}+1\right)\left(T_{\mathrm{st}}-T_{\mathrm{i}}\right)
$$

\section{Analysis of the principal phase of DIC hydrothermal treatment}

At the beginning of the principal phase, the equilibrium temperature of the steam is already reached by the temperature of starch. Consequently, during this period there is no heat transfer, but it is the moisture content uptake which dominates the exchanges. The mass transfer occurs by the difference in water concentration between liquid film, resulting in the condensation of vapor, and the granules surface. The water movement induces significant gradients of pressure. We can express the potential of transfer in terms of difference in partial pressure. The mass transfer equation is given as:

$$
\frac{d m}{d t}=k_{\mathrm{p}} A\left(P_{\mathrm{st}}-P\right)
$$

Where $k_{\mathrm{p}}$ is the mass transfer coefficient when the chemical potential is expressed in partial pressure difference $\left(\mathrm{s} \mathrm{m}^{-1}\right)$; A is the exchange surface $\left(\mathrm{m}^{2}\right), P_{\text {st }}$ is the steam pressure $(\mathrm{Pa}), P$ is the vapor pressure that would be in equilibrium with the water within starch granules $(\mathrm{Pa})$.

Generally, the mass transfer coefficients are cited using the driving forces in term of concentration. As the concentration is proportional to the partial pressure, the equilibrium relationship can be expressed in terms of partial pressure. Noting that for an ideal gas, the concentration units can be converted into partial pressure units as follows by the equation, $c=\frac{P}{R T}$. When the phenomenon is isothermal, there is no practical difference between using partial pressure and concentration as driving force. The equation of transfer can be written as follows and $k_{\mathrm{p}}=M k_{\mathrm{c}} / R T$. Where,

$$
\frac{d m}{d t}=k_{\mathrm{p}} A\left(P_{\mathrm{st}}-P\right) \approx M k_{\mathrm{c}} A\left(\frac{P_{\mathrm{st}}}{R T_{\mathrm{st}}}-\frac{P}{R T}\right)
$$

$M$ is the molecular mass of water $\left(\mathrm{kg} \mathrm{kmol}^{-1}\right), k_{\mathrm{c}}$ is the mass transfer coefficient $\left(\mathrm{m} \mathrm{s}^{-1}\right), R$ is the universal gas constant $\left(\mathrm{J} \mathrm{kmol}^{-1} \mathrm{~K}^{-1}\right), T$ is the starch granules temperature $(\mathrm{K})$ and $T_{\mathrm{st}}$ is the steam temperature $(\mathrm{K})$.

Eqn (6) constitutes the base of the model of moisture content variation in the starch layer with processing time. To develop the model, it is necessary to establish a relationship between the water vapor pressure in equilibrium with the starch granules and the water content through a water activity function. We used the sorption isotherm of native maize starch obtained at $25{ }^{\circ} \mathrm{C}$ (Fig. 3). $a_{\mathrm{w}}$ is the ratio of the partial vapor pressure in equilibrium with the water in the starch granules and the vapor pressure of water at starch temperature.

$$
P=P_{\mathrm{s}}(T) a_{\mathrm{w}}
$$

Where $P_{\mathrm{s}}(T)$ is the vapor pressure of water at the starch temperature $(\mathrm{Pa})$ and $a_{\mathrm{w}}$ is the water activity. 


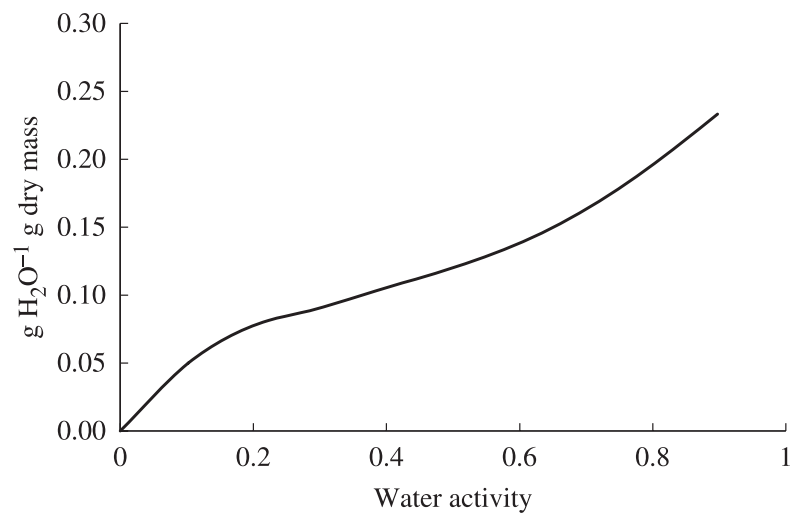

Figure 3 Sorption isotherm of standard maize starch at $25^{\circ} \mathrm{C}$.

$$
\frac{d m}{d t}=k_{\mathrm{p}} A\left[P_{\mathrm{st}}-P_{\mathrm{s}}(T) a_{\mathrm{w}}\right]
$$

A functional relationship between the water activity $\left(a_{\mathrm{w}}\right)$ and moisture content must be chosen from the sorption isotherms. The sorption isotherms are nonlinear, but Stapley et al. (1999) approximated them satisfactorily by a linear relation in the range of moisture content considered in their study. For our treatment where the moisture content varied between 0.1 and 0.3 (dry basis), the approximation of water activity vs. moisture contents by a linear function was also satisfactory. However, it should be noted that the sorption isotherms were determined at $25^{\circ} \mathrm{C}$ and the DIC treatment is carried out at $100{ }^{\circ} \mathrm{C}(1 \mathrm{bar}), 122{ }^{\circ} \mathrm{C}$ (2 bar) and $135^{\circ} \mathrm{C}$ (3 bar).

$$
a_{\mathrm{w}}=\gamma W_{\mathrm{db}}
$$

Where $\gamma$ is the coefficient of water activity.

Once the temperature equilibrium between the starch and the surrounding steam is established, the starch temperature is identical to that of the steam. In this case, the vapor pressure of water at the starch temperature,
$P_{\mathrm{s}}(T)$, would be equal to the saturated steam pressure at the same temperature.

$$
P_{\mathrm{s}}(T)=P_{\mathrm{st}}
$$

From eqn (1) $m=m_{\mathrm{d}}\left(1+W_{\mathrm{db}}\right)$ and combining eqns (8), (9), (10), the equation of mass transfer can be rewritten as follows:

$$
\frac{d m}{d t}=k_{\mathrm{p}} A P_{\mathrm{st}}\left(1-\gamma W_{\mathrm{db}}\right)=m_{\mathrm{d}} \frac{d W_{\mathrm{db}}}{d t}
$$

After integration, it results in:

$$
W_{\mathrm{db}}=\frac{1}{\gamma}-\left(\frac{1}{\gamma}-W_{\mathrm{dbo}}\right) e^{-\left[\frac{\left.\gamma\left(\frac{\gamma \mathrm{p}}{m_{\mathrm{d}}}\right) A P_{\mathrm{st}}\right] t}{m}\right.}
$$

The resolution of this equation was obtained by solving numerically eqn (12) by using SIGMAPLOT software on the gravimetric data of Fig. 1. The parameters of the model were deduced by using a non-linear least squares algorithm. The three given parameters are: $\gamma, W_{\mathrm{dbo}}$ and $\frac{\gamma k_{\mathrm{p}} A P_{\mathrm{st}}}{m_{\mathrm{d}}}$. From the third parameter, the value of $k_{\mathrm{p}} A$ was deduced. The mass transfer coefficient $k_{\mathrm{p}}$ was calculated by taking the specific surface area of standard maize starch given by Juszczak et al. (2002) corresponding to $0.687 \mathrm{~m}^{2} \mathrm{~g}^{-1}$ and $22 \mathrm{~g}$ of starch used during in our experiments.

\section{Comparison of model with experimental data}

Table 1 shows $W_{\text {dbo }}$ deduced by experimental measurements and that calculated using eqn 4 , i.e. at the end of the initial heating phase (see Fig. 2a), and that calculated from the model fit (eqn 12) corresponding to the initial moisture content in the principal phase of DIC treatment (see Fig. 2b). The values of $W_{\text {dbo }}$ predicted by the model (eqn 4, using $C_{\mathrm{po}}=1.58 \mathrm{~kJ} \mathrm{~kg}^{-1} \mathrm{~K}^{-1}$; $\lambda=2500.8-2.48 T_{\mathrm{st}}\left(\mathrm{kJ} \mathrm{kg}^{-1}\right) ; T_{\mathrm{st}}=100{ }^{\circ} \mathrm{C}$ and $\left.T_{\mathrm{i}}=40{ }^{\circ} \mathrm{C}\right)$ are 0.184 for 1 bar $\left(100^{\circ} \mathrm{C}\right), 0.200$ for 2 bar $\left(122^{\circ} \mathrm{C}\right)$ and 0.215 for $3 \operatorname{bar}\left(135^{\circ} \mathrm{C}\right)$.

The comparison of $W_{\mathrm{dbo}}$ obtained from eqn 4 with experimental data shows that the predicted values are

Table 1 Experimental and fitted parameters of Eqs.4 and 12

\begin{tabular}{lccc}
\hline Parameters & 1 bar & 2 bar & 3 bar \\
\hline$W_{\text {dbo }}$ (experimental) & $0.135 \pm 0.002$ & $0.155 \pm 0.006$ & $0.144 \pm 0.006$ \\
$W_{\text {dbo }}$ (eqn 4) & $0.184 \pm 0.009$ & $0.200 \pm 0.008$ & $0.215 \pm 0.007$ \\
$W_{\text {dbo }}$ (eqn 12) & $0.127 \pm 0.002$ & $0.141 \pm 0.005$ & $0.133 \pm 0.003$ \\
$\gamma$ & $5.86 \pm 0.03$ & $3.71 \pm 0.05$ & $3.36 \pm 0.20$ \\
$\gamma k_{\mathrm{p}} A P_{\mathrm{st}} / M_{\mathrm{d}}\left(\mathrm{s}^{-1}\right)$ & $0.155 \pm 0.018 \times 10^{-2}$ & $0.029 \pm 0.079 \times 10^{-2}$ & $0.030 \pm 0.006 \times 10^{-2}$ \\
$R^{2}$ & 0.98 & 0.93 & 0.98 \\
$k_{\mathrm{p}} A\left(\mathrm{~ms}^{-1}\right)$ & $5.16 \times 10^{-9}$ & $0.76 \times 10^{-9}$ & $0.58 \times 10^{-9}$ \\
$k_{\mathrm{p}}\left(\mathrm{s} \mathrm{m}^{-9}\right)$ & $3.42 \times 10^{-10}$ & $0.50 \times 10^{-10}$ & $0.38 \times 10^{-10}$ \\
$k_{\mathrm{c}}\left(\mathrm{m} \mathrm{s}^{-1}\right)$ & $5.89 \times 10^{-5}$ & $0.77 \times 10^{-5}$ & \\
\hline
\end{tabular}

$R^{2}$ is the regression coefficient. 
higher. This difference can be explained by the fact that eqn 4 considers that all steam condensation occurred on the starch thin layer and thus the condensation of water on the walls of processing vessel was neglected. This difference could be also because of eqn 4 considers only the variation in the sensible heat caused by the absorption of the latent heat of condensation and neglects the other forms of heat such as the heat of absorption of liquid water into the granules and the heat of fusion of crystalline structure. In contrast, the values of $W_{\mathrm{dbo}}$ calculated from the model fit (eqn 12) corresponding to the initial moisture content of the principal phase show good agreement with experimental values.

The values of water activity coefficient $(\gamma)$ obtained from the model decrease when processing pressure increases; 5.86 (dry basis) $^{-1}$ for 1 bar, 3.71 (dry basis) $^{-1}$ and 3.36 (dry basis) $^{-1}$ for 2 and 3 bar, respectively. Comparison between $\gamma$ obtained from the mathematical model at different pressures, and that calculated from the sorption isotherm cannot be done. In fact, the sorption isotherms were measured at $25{ }^{\circ} \mathrm{C}$, whereas absorption of water during DIC treatment is done at $100{ }^{\circ} \mathrm{C}$ (1 bar), $120{ }^{\circ} \mathrm{C}$ ( 2 bar) and $135{ }^{\circ} \mathrm{C}$ (3 bar). However, the $\gamma$ value obtained from the mathematical model has the same magnitude as that obtained from the sorption isotherm of standard native maize starch (4.08 $\left.(\text { dry basis })^{-1}\right)$.

From Table 1, it can be seen that for 1 bar processing pressure, the mass transfer coefficient is of $5.89 \times 10^{-5}$ $\mathrm{m} \mathrm{s}^{-1}$. When the processing pressure increases, $k_{\mathrm{c}}$ greatly diminishes to $0.92 \times 10^{-5} \mathrm{~m} \mathrm{~s}^{-1}$ and $0.77 \times 10^{-5} \mathrm{~m} \mathrm{~s}^{-1}$ for 2 and 3 bar respectively. One could expect an increase in $k_{\mathrm{c}}$ with increasing pressure and temperature. Stapley et al. (1999) observed the same tendency for steaming of whole wheat grain. The predicted mass transfer coefficient was lower at 2 bar than at 1 bar.

The mass transfer fitted by the model does not take into account the physico-chemical transformations of starch during the treatment. Indeed, the analysis of mass transfer is more difficult, if physico-chemical transformations take place, whose kinetics are also correlated with moisture content and temperature. According to Watanabe et al. (2001), the water migration is not driven by the gradient of moisture content but by the water demand, which is the difference between the potential maximum moisture (defined by the extent of gelatinisation) and the existing moisture content; this would explain why pre-cooked rice absorbs more water (higher water demand) than polished rice by immersion at the same temperature. The reduction in the mass transfer coefficient is certainly related to the progression of the gelatinisation phenomenon when the temperature increases. A recent work (Legros et al., 2005) showed important modifications in thermal transition characteristics of DIC treated maize starch at various steam

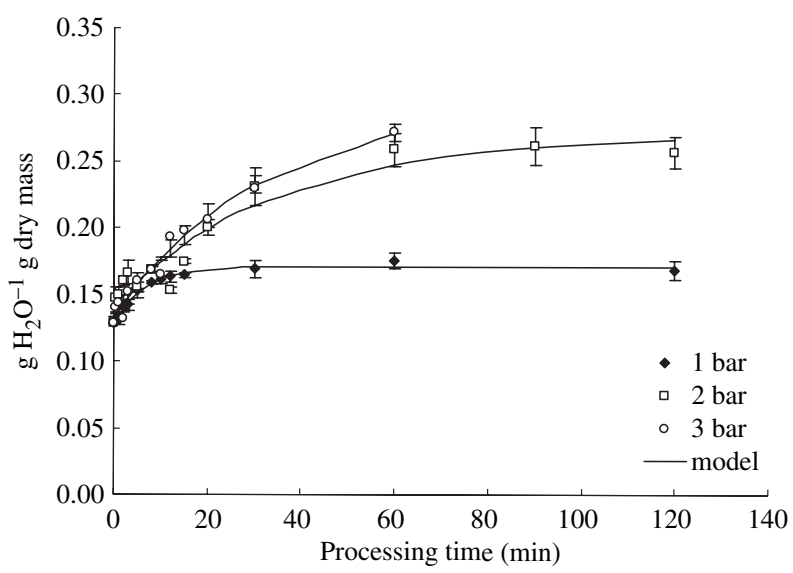

Figure 4 Comparison of predicted moisture content of 'Détente Instantanée Contrôlée' treated standard maize starch at 1,2 and 3 bar with experimental results.

pressures and treatment times. An increase in the gelatinisation degree was observed after DIC treatment when pressure level and processing time increased. For a same processing time $(60 \mathrm{~min})$, the gelatinisation degree was $21.3 \%$ for starch treated at 1 bar, whereas it was $39.5 \%$ for starch treated at 2 bar. A processing time of 20 min was sufficient to obtain a total gelatinisation for starch treated at 3 bar. Gomi et al. (1998), using PFGNMR method, observed that water diffusivity in heated starch/water mixtures increases as the temperature is raised as long as gelatinisation does not occur. At temperatures which exceed the gelatinisation temperature, water diffusivity decreases.

Fig. 4 compares the experimental data with the predicted results. The fit to data shows good agreement between the predicted and experimental data. The regression coefficient is higher than 0.93 for the three processing pressures.

\section{Conclusion}

The moisture content follow-up of the starch during DIC treatment for various processing pressure was carried out until saturation (or equilibrium). This state is reached when the equilibrium between the starch layer and the surrounding steam is established. The results showed that the moisture content increases as processing time increases and reached equilibrium for the pressures of 1 and 2 bar during 30 and $60 \mathrm{~min}$, respectively. During DIC hydrothermal treatment, the heat transfer is carried out by absorption of the latent heat of condensation. The mass transfer model was based on two steps of DIC treatment. This model is based on experimental measurements of moisture content measured during DIC treatment of starch layer. The 
predicted data were found to be in good agreement with experimental data. The mass transfer coefficient deduced from the model decreases as the processing pressure increases. This reduction supposes that the mass transfer phenomenon is not only controlled by a simple resistance to the mass transfer (or to gradient of moisture content), but also by the progression of gelatinisation phenomenon, which takes importance when the processing pressure exceeds 1 bar. The moisture contents, obtained using the mathematical model, were correlated with the results obtained by DSC (Zarguili, 2006). These results allow to connect the thermal transition of the starch granules to the conditions of DIC treatment and thus to identify the required DIC conditions for a partial or total fusion.

\section{Nomenclature}

A: $\quad$ surface exchange $\left(\mathrm{m}^{2}\right)$;

$a_{\mathrm{w}}$ : water activity;

$C$ : molar concentration $\left(\mathrm{kmol} \mathrm{m}^{-3}\right)$;

$C_{\text {po }}$ : $\quad$ specific heat of untreated starch $=1.58 \mathrm{~kJ} \mathrm{~kg}^{-1} \mathrm{~K}^{-1}$;

$k_{\mathrm{c}}$ : $\quad$ mass transfer coefficient $\left(\mathrm{m} \mathrm{s}^{-1}\right)$;

$k_{\mathrm{p}}$ : mass transfer coefficient, when chemical potential is expressed in partial pressure;

$k_{\mathrm{p}} \quad=M k_{\mathrm{c}} / R T\left(\mathrm{~s} \mathrm{~m}^{-1}\right)$;

$M: \quad$ molecular mass of water $\left(\mathrm{kg} \mathrm{kmol}^{-1}\right)$;

$m: \quad$ total mass of treated starch at $t$ time $(\mathrm{kg})$;

$m_{\mathrm{o}}$ : total mass of the starch in the end of the initial phase $(\mathrm{kg})$;

$m_{\mathrm{i}}: \quad$ initial total mass of untreated starch $(\mathrm{kg})$;

$m_{\mathrm{d}}: \quad$ mass of dry starch $(\mathrm{kg})$;

$P_{\mathrm{s}}(T)$ : vapor pressure of water at the starch temperature $(\mathrm{Pa})$;

$P_{\text {st }}: \quad$ steam pressure $(\mathrm{Pa})$;

$P: \quad$ vapor pressure in equilibrium with the water within the grain $(\mathrm{Pa})$;

$R$ : $\quad$ universal gas constant $\left(\mathrm{J} \mathrm{kmol}^{-1} \mathrm{~K}^{-1}\right)$;

$T: \quad$ starch granules temperature $(\mathrm{K})$;

$T_{\mathrm{st}}$ : $\quad$ temperature of saturated vapor $(\mathrm{K})$;

$T_{\mathrm{i}}$ : $\quad$ initial temperature $(\mathrm{K})$;

$W_{\mathrm{db} 0}$ : moisture content of starch granules at the end of the initial heating phase (dry basis);

$W_{\mathrm{db}}$ : moisture content (dry basis);

$W_{\mathrm{i}}$ : initial untreated starch moisture content (dry basis);

$\lambda$ : enthalpy of condensation/absorption $\left(\mathrm{kJ} \mathrm{kg}^{-1}\right)$;

$\gamma$ : coefficient of water activity (dry basis) $)^{-1}$;

\section{References}

Barron, C., Buleon, A., Colonna, P. \& Della Valle, G. (2000). Structural modifications of low hydrated pea starch subjected to high thermomechanical processing. Carbohydrate Polymers, 43, 171-181.
Brümmer, T., Meuser, F., Van Lengerich, B. \& Niemann, C. (2002). Effect of extrusion cooking on molecular parameters of corn starch. Stärke, 54, 1-8.

Collado, L.S. \& Corke, H. (1999). Heat-moisture treatment effects on sweet potato starches differing in amylose content. Food Chemistry, 65, 329-346.

Fang, C. \& Chinnan, M.S. (2004). Kinetics of cowpea starch gelatinization and modeling of starch gelatinization during steaming of intact cowpea seed. Lebensmittel-Wissenschaft und-Technologie, 37, 345-354.

Gomi, Y., Fukuoka, M., Mihori, T. \& Watanabe, H. (1998). The rate of starch gelatinization as observed by PFG-NMR measurement of water diffusivity in rice starch/water mixtures. Journal of Food Engineering, 36, 359-369.

Gunarante, A. \& Hoover, R. (2002). Effect of heat-moisture treatment on the structure and physical properties of tuber and root starches. Carbohydrate Polymers, 49, 425-437.

Hoover, R. \& Manuel, H. (1996). Effect of heat-moisture treatment on the structure and physicochemical properties of normal maize, waxy maize, dull waxy maize and amylomaize $\mathrm{V}$ starches. Journal of Cereal Science, 23, 153-162.

Jacobs, H., Mischenko, N., Koch, M.H.J., Eerlingen, R.C., Delcour, J.A. \& Reynaers, H. (1998). Evaluation of the impact of annealing on gelatinization at intermediate water content of wheat and potato starches: a differential scanning calorimetry and small angle X-ray scattering study. Carbohydrate Research, 306, 1-10.

Juszczak, L., Fortuna, T. \& Wodnicka, K. (2002). Characteristics of cereal starch granules surface using nitrogen adsorption. Journal of Food Engineering, 54, 103-110.

Kulp, K. \& Lorenz, K. (1981). Heat-moisture treatment of starches. I. Physicochemical properties. Cereal Chemistry, 58, 46-48.

Legros, A., Zarguili, I., Maache-Rezzoug, Z., Loisel, C. \& Doublier, J.L. (2005). Effet du procédé de détente instantanée contrôlée sur les propriétés structurales et fonctionnelles d'amidon de mais standard. 10th Congress of the French Society of Chemical Engineering (SFGP 2005), Toulouse, France, 20-22 Septembre. Published in "Récents Progrès en Génie des Procédés", N 92, Ed. Lavoisier, Paris, France.

Lim, S.T., Chang, E.H. \& Chung, H.J. (2001). Thermal transition characteristics of heat-moisture treated corn and potato starches. Carbohydrate Polymers, 46, 107-115.

Loisel, C., Maache-Rezzoug, Z., Esneault, C. \& Doublier, J.L. (2006). Effect of hydrothermal treatment on the physical and rheological properties of maize starches. Journal of Food Engineering, 73, 45-54.

Maache-Rezzoug, Z., Rezzoug, S.A. \& Allaf, K. (2002). Development of a new drying process: dehydration by cyclical pressure drops (D.D.S). Application to the collagen gel. Journal of Drying Technology, 20, 109-130.

Maruta, I., Kurahashi, Y., Takayano, R. et al. (1994). Reducedpressurized heat-moisture treatment: a new method for heatmoisture treatment of starch. Stärke, 46, 177-181.

Mercier, C. (1987). Comparative modifications of starch and starchy products by extrusion cooking and drum-drying. In: Pasta and Extrusion Cooked Foods (edited by C. Mercier \& C. Cantarelli). Pp. 120-130. London: Elsevier.

Rezzoug, S. A., Maache-Rezzoug, Z., Mazoyer, J. \& Allaf, K. (2000). Effect of instantaneous controlled decompression proccess on hydration capacity of scleroglucan. Optimisation of operating conditions by response surface methodology. Carbohydrate Polymers, 42, 73-84.

Singh, N., Singh, J., Kaur, L., Sodhi, N. S. \& Gill, B.S. (2003). Morphological thermal and rheological properties of starches from different botanical sources. Food Chemistry, 81, 219-231.

Stapley, A.G.F., Hyde, T.M., Gladden, L.F. \& Fryer, P.J. (1997). NMR imaging of the wheat grain cooking process. International Journal of Food Science and technology Technology, 32, 355375 . 
Stapley, A.G.F., Landman, K.A., Please, C.P. \& Fryer, P.J. (1999). Modelling the steaming of whole wheat grains. Chemical Engineering Science, 54, 965-975.

Takeuchi, S., Maeda, M., Gomi, Y., Fukuoka, M. \& Watanabe, H. (1997). An application of magnetic resonance imaging to the real time measurement of the change of moisture profile in a rice grain during boiling. Journal of Food Engineering, 33, 181-192.

Tester, R.F., Debon, S.J.J. \& Sommerville, M.D. (2000). Annealing of maize starch. Carbohydrate Polymers, 42, 287-299.

Turhan, M. \& Sağol, S. (2004). Abrupt changes in the rates of processes occurring during hydrothermal treatment of whole starchy foods around the gelatinization temperature-a review of the literature. Journal of Food Engineering, 62, 365-371.
Vallous, N.A., Gavrielidou, M.A., Karapantsios, T.D. \& Kostoglou, M. (2002). Performance of a double drum dryer for producing pregelatinized maize starches. Journal of Food Engineering, 51, 171-183.

Watanabe, H., Fukuoka, M., Tomiya, A. \& Tomowo, M. (2001). New non-Fickian diffusion model for water migration in starchy food during cooking. Journal of Food Engineering, 49, 1-6.

Zarguili, I. (2006). Etude de l'effet de l'hydrotraitement DIC sur modifications structurales et fonctionnelles des amidons de différentes origines botaniques. Phd Thesis, France: Université de La Rochelle. Zarguili, I., Maache-Rezzoug, Z., Loisel, C. \& Doublier, J.L. (2006). Influence of D.I.C. hydrothermal process conditions on the gelatinization properties of standard maize starch. Journal of Food Engineering, 77, 454-461. 